\title{
Inhibition of the renin-angiotensin system during fetal kidney development
}

\author{
Eujin Park, MD \\ Department of Pediatrics, Kangnam Sacred Heart Hospital, Hallym University College of Medicine, Seoul, Korea
}

\begin{abstract}
Key message
Fetal exposure to renin-angiotensin system (RAS) inhibitors leads to short- and long-term kidney complications.

Women of reproductive age who are absolutely indicated for RAS inhibitors should be adequately informed of the risks for the duration of treatment.
\end{abstract}

The renin-angiotensin system (RAS) regulates fluid and salt reabsorption as well as vascular tone and cardiac contractility to maintain fluid volume, arterial pressure, and tissue perfusion. Inappropriate RAS activation causes fluid retention, blood pressure elevations, and vascular as well as tissue dysfunction, leading to end-organ damage. Angiotensin II (ANG II) is derived from angiotensinogen via the sequential actions of circulating renin and angiotensin-converting enzyme (ACE). ANG II acts on the kidneys, blood vessels, and heart, largely via $G$ proteincoupled receptor type $\left.1(\mathrm{AT} 1 \mathrm{R}) .{ }^{1}\right)$ A prolonged excessive increase in circulating ANG II causes sodium and fluid retention, vasoconstriction, and kidney and heart hypertrophy and fibrosis, all of which contribute to the development of hypertension, chronic kidney disease, and heart failure. The protective effects of various RAS-inhibiting medications on the kidneys and heart have been well documented, and such medications (targeting renin, ACE, or ANG II receptors) are widely prescribed. ${ }^{2)}$

However, normal RAS function is also essential, for example during postural change, hypovolemia, and most relevant to the current context, fetal development. The high levels of circulating renin and ANG II during fetal life maintain adequate perfusion and stimulate the growth promoting action of the fetal kidney. ${ }^{3)}$ If the fetal RAS becomes inactivated, the decreased systemic blood pressure leads to decreased renal perfusion, renal ischemia, and abnormal renal tubule development. Nephrogenesis begins around 8 weeks and ends around 36 weeks of gestation; such changes become irreversible after this time. ${ }^{4)}$ Renal lesions resulting from an inactivated RAS are commonly observed in inherited renal tubular dysgenesis (RTD), which is caused by mutations in the genes encoding RAS components including angiotensinogen $(A G T)$, renin $(R E N), A C E(A C E)$, and $\mathrm{AT}_{1} \mathrm{R}$
(AGTR1). Such mutations ablate ANG II production or activity, thereby inactivating the negative feedback circuit regulating the RAS. ${ }^{5)}$ To date, few patients exhibiting such mutations have survived the neonatal period. ${ }^{\text {) }}$

Similar pathogenic mechanisms have been observed in fetuses exposed to RAS-inhibiting medications (e.g., ACE inhibitors or ANG II receptor blockers) in utero, a major cause of secondary RTD. Fetal complications resulting from the use of RAS-inhibiting medications during pregnancy include oligohydramnios, intrauterine growth retardation, renal failure, arterial hypotension, respiratory failure, Potter syndrome (facial dysmorphism, redundant skin, limb-positioning defects, arthrogryposis, and lung hypoplasia), and death. Approximately half of the fetuses exposed to RAS-inhibiting medication in utero have longterm kidney complications, while 10\% have a particularly poor prognosis (e.g., end-stage renal disease and death). ${ }^{7)}$

In this issue of Clinical and Experimental Pediatrics, Gang et al. ${ }^{8)}$ report a case of neonatal RTD due to ANG II receptor blocker exposure in utero during the entire pregnancy. The patient died soon after birth of refractory hypotension and renal failure. Two major factors contributing to poor renal prognosis in this case are: exposure to ANG II receptor blockers, which block AT1R more potently and or longer than other RAS-inhibiting medications; and exposure to RAS-inhibiting medications during the second or third trimester (or the entire pregnancy) versus during the first trimester. ${ }^{7)}$ To prevent such outcomes, women of reproductive age should not be routinely prescribed RASinhibiting medications. If such drugs are absolutely and unavoidably indicated, the patient should be adequately informed of the risks and guaranteed the provision of contraception for the duration of the prescription. Most definitively, RAS-inhibiting medications should not be prescribed to pregnant women, and doctors should elicit from all pregnant women a list of their current medications to ensure that their inappropriate use may be discontinued as soon as possible."

In conclusion, despite the passage of 30 years since the first report of fetal exposure to ACE inhibitors, ${ }^{10)}$ neonatal complications due to in utero exposure to RAS-inhibiting medications

Corresponding author: Eujin Park, MD. Department of Pediatrics, Kangnam Sacred Heart Hospital, Hallym University College of Medicine, 1 Singil-ro, Yeongdeungpogu, Seoul 07441, Korea 
continue to occur. This is a tremendous and avoidable tragedy impacting families and the healthcare providers tasked with their care. Given the continual development of novel medications that effectively block RAS activity and an anticipated increase in demand due to the aging population, this case report repre. sents an opportunity to raise clinician awareness regarding the significant risks of prescribing such drugs to women of reproductive age.

\section{Conflicts of interest}

No potential conflict of interest relevant to this article was reported.

See the article "Secondary renal tubular dysgenesis in a newborn exposed to angiotensin II receptor antagonist during gestation" via https://doi.org/10.3345/cep.2020.00752 .

\section{References}

1. Brewster UC, Perazella MA. The renin-angiotensin-aldosterone system and the kidney: effects on kidney disease. Am J Med 2004;116:263-72.

2. Verdecchia P, Angeli F, Mazzotta G, Gentile G, Reboldi G. The renin angiotensin system in the development of cardiovascular disease: role of aliskiren in risk reduction. Vasc Health Risk Manag 2008;4:971-81.

3. Gomez RA, Norwood VF. Developmental consequences of the reninangiotensin system. Am J Kidney Dis 1995;26:409-31.
4. Hinchliffe SA, Sargent PH, Howard CV, Chan YF, van Velzen D. Human intrauterine renal growth expressed in absolute number of glomeruli assessed by the disector method and Cavalieri principle. Lab Invest 1991; 64:777-84.

5. Gubler MC, Antignac C. Renin-angiotensin system in kidney development: renal tubular dysgenesis. Kidney Int 2010;77:400-6.

6. Uematsu M, Sakamoto O, Nishio T, Ohura T, Matsuda T, Inagaki T, et al. A case surviving for over a year of renal tubular dysgenesis with compound heterozygous angiotensinogen gene mutations. Am J Med Genet A 2006;140:2355-60.

7. Bullo M, Tschumi S, Bucher BS, Bianchetti MG, Simonetti GD. Pregnancy outcome following exposure to angiotensin-converting enzyme inhibitors or angiotensin receptor antagonists: a systematic review. Hypertension 2012;60:444-50.

8. Gang MH, Lee YW, Chang M. Secondary renal tubular dysgenesis in a newborn exposed to angiotensin II receptor antagonist during fetal life. Clin Exp Pediatr 2020 Jul 21 [Epub]. https://doi.org/10.3345/ cep.2020.00752.

9. Whelton PK, Carey RM, Aronow WS, Casey DE Jr, Collins KJ, Dennison Himmelfarb C, et al. 2017 ACC/AHA/AAPA/ABC/ACPM/AGS/APhA/ ASH/ASPC/NMA/PCNA Guideline for the prevention, detection, evaluation, and management of high blood pressure in adults: a report of the American College of Cardiology/American Heart Association Task Force on Clinical Practice Guidelines. Hypertension 2018;71:e13-115.

10. Duminy PC, Burger PD. Fetal abnormality associated with the use of captopril during pregnancy. S Afr Med J 1981;60:805.

How to cite this article: Park E. Inhibition of the renin-angiotensin system during fetal kidney development. Clin Exp Pediatr 2021;64:121-2. https://doi.org/10.3345/cep.2020.01228 